\title{
Experimental Verification of the Theoretical Aging of Vacuum Insulated Panels
}

\author{
Mahsa Nikafkar ${ }^{1}$ and Umberto Berardi ${ }^{2}$ \\ Dep. Architectural Science, Ryerson University, 350 Victoria Street, Toronto, M5B 2K3, ON, Canada \\ ${ }^{1}$ mahsa.nikafkar@ryerson.ca ${ }^{2}$ uberardi@ryerson.ca
}

\begin{abstract}
Vacuum Insulation Panels (VIPs) encompass a higher thermal resistance per unit of thickness compared to any other kind of insulation. However, their aging has often shown some critical concerns among stakeholders. To support the broader use of VIPS in the building sector, a comprehensive analysis of the physical properties of VIPs and in particular of their thermal conductivity over longperiods is required. This research investigates the effect of the temperature and relative humidity on the service life and thermal conductivity of VIPs. The scope of this study is to validate existing aging models for VIPS. First, the experimental results of the thermal conductivity for five VIPs both in pristine and in laboratory-accelerated conditions are described. Then, an analytical aging method is employed to validate the collected data. Results show that the aging has a more significant impact on the performance of VIPs with a core of fiberglass-core than with VIPs with a core of fumed silica.
\end{abstract}

Keywords: Vacuum Insulation Panels, Durability, Service Life Prediction, Thermal Conductivity.

\section{Introduction}

It is widely acknowledged that buildings account for more than $32 \%$ of total global energy consumption and contribute to $19 \%$ of the GHG emissions. The global energy-related $\mathrm{CO}_{2}$ emissions from the building sector more than doubled between 1970 and 2010, and are projected to increase by another twofold by 2050 (Berardi, 2017). Several researches confirmed that the heat transfer (i.e. losses) through the building envelope is the most significant energy factor for building efficiency as such, significant attention exists for super-insulating materials. High-performance materials such as Vacuum Insulation Panels (VIPs) offer a high thermal resistance value with minimized thickness, thanks to their low thermal conductivity $(0.003$ $0.005 \mathrm{~W} / \mathrm{mK}$ ) which is about five times lower than that of traditional insulation materials (Johansson et al., 2014; Karami et al., 2015). VIPs are non-homogeneous insulation materials consisting of a porous core which is evacuated from air and vapor, tightened, and then heatsealed. VIPs materials are in the early market stages in the building sector and data about their thermal performance over the building lifetime is missing (Baetens et al., 2010; Kalnæs and Jelle, 2014).

Consequently, many international research efforts have focused on the thermal properties of VIPs over time (Wegger et al., 2011; Isaia et al., 2017; Mac Lean et al., 2017). Several works have proposed methods to predict the service life of VIPs with Fumed Silica (FS) core and on the development of models to determine their moisture content. Theoretical approaches to predict their long-term performances by means of interpreting accelerated aging tests done in laboratories have also been proposed (Table 1). The increase in pressure and humidity inside a VIP panel over time is often pointed as the main aging mechanism for VIPs (Schwab et al., 2005).

The objective of this paper is to evaluate experimentally the thermal conductivity of some VIP after several aging exposures and to assess the accuracy of existing thermal conductivity aging models through verification of collected results for different core materials of VIPs. 
Table 1. Literature review summary of previous studies related to the topic of the present paper.

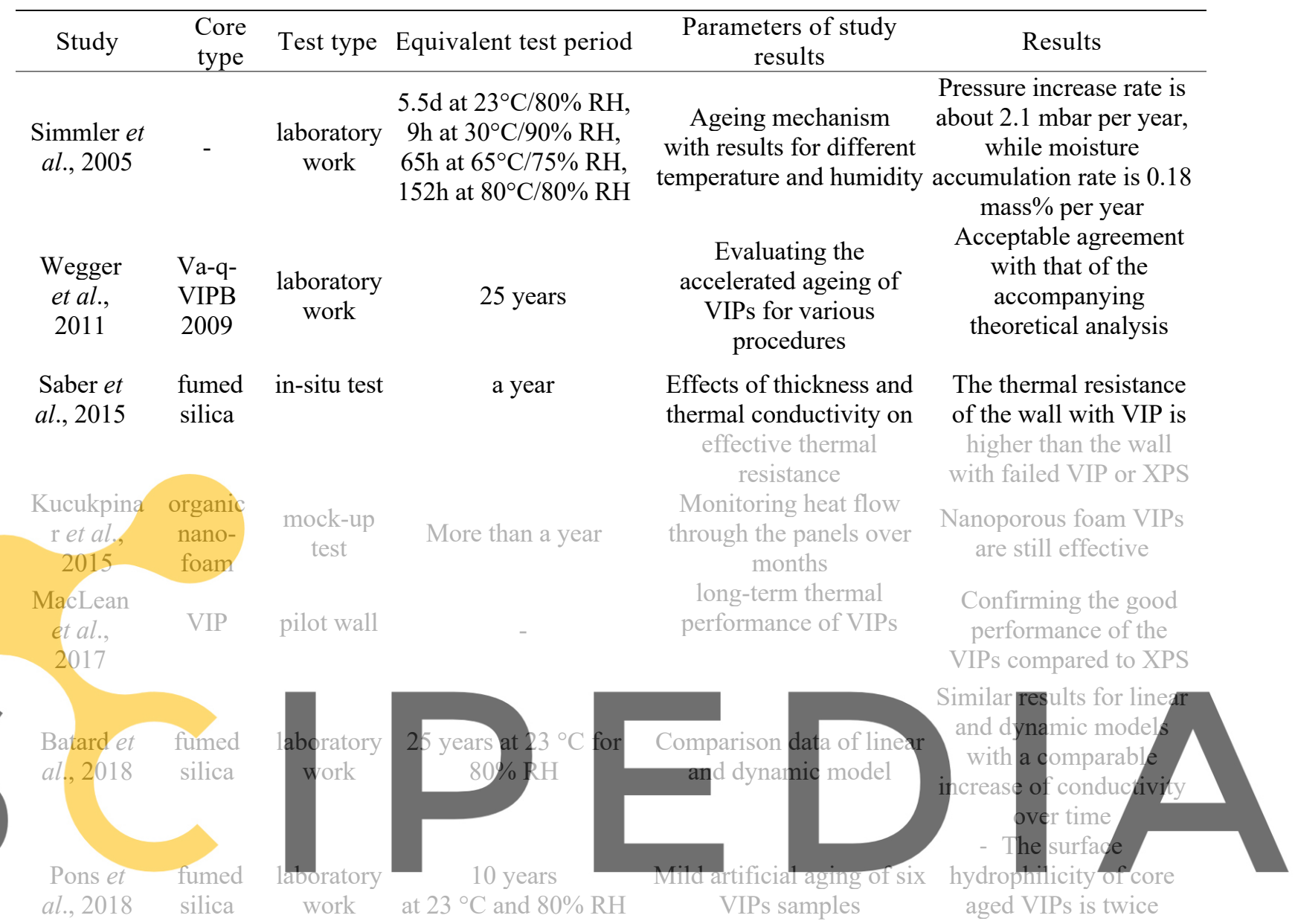

\section{Theoreticall Background and Research Methodology}

The thermal conductivity of VIPs is a critical characteristic to study. Solid conduction, air convection, and radiations determine the primary heat transfer mechanisms that control the insulation capacity of the panel. The thermal conductivity of VIPs has been proposed as a summation of different effects as reported in Eq. (1) (Wegger et al., 2010; Alotaibi et al., 2014):

$$
\lambda_{\text {tot }}=\lambda_{s}+\lambda_{g}+\lambda_{r}+\lambda_{w v}+\lambda_{w}+\lambda_{\text {cop }}
$$

where $\lambda_{s}$ represents solid conduction through the material, $\lambda_{g}$ shows gas conduction through the porous of material, $\lambda_{r}$ presents radiation heat transfer between inner pore, $\lambda_{w v}$ is the permeation of air and moisture through pores, $\lambda_{w}$ is the thermal conduction over time based on adsorbed water within the core material, and $\lambda_{c o p}$ is the thermal conductivity accounting for second-order effects between the mentioned thermal conductivities. In Eq. (1), the $\lambda_{w v}$ and $\lambda_{c o p}$ components have a lower value compared to other terms, and can often be neglected. The gas thermal conductivity is independent of the density, and its reduction provides a significant opportunity to improve the performance of the VIPs (Kwon et al., 2009).

A different way to express the thermal conductivity of VIP is by taking into account their aging, as described by Eq. 2 (Caps et al., 2008): 


$$
\lambda_{\text {tot }}=\lambda_{\text {init }}+\frac{\lambda_{0}}{1+\frac{0.032}{p \Phi}}+b X_{w}(t)=\lambda_{\text {init }}+\frac{\lambda_{0}}{1+\frac{0.032}{p \Phi}}+c\left(1-\exp \left(-\frac{t}{\tau_{w}}\right)\right)
$$

where $\lambda_{\text {int }}$ is a summation of solid and radiation thermal conductivities, $\lambda_{0}$ is the conductivity of air for atmospheric pressure, $p$ is gas pressure, and $\Phi$ is the pore size of the pores.

As evident, to fully study the behaviour of Eg (2), long periods would be needed. Consequently, accelerated aging methods are often used to find failure modes in a shorter time, which is resulted after many years at a normal temperature. In this study, exposure of VIP to elevated temperature was used to age several VIP samples. The increase of temperature could grow the kinetic reaction rate within the molecules of materials which causes chemical deprivation. For this purpose, accelerated aging temperatures of building materials are often select around $70{ }^{\circ} \mathrm{C}$ (Jelle, 2012; Kunic, 2012). Arrhenius law was used to calculate the time equivalent to 25 years of aging. To determine the relationship between the aging test condition and the real condition, accelerated factor $\left(A F_{\text {temp }}\right)$ was presented:

$$
A F_{\text {temp }}=e^{-\frac{E_{a}}{K}\left(\frac{1}{T_{A}}-\frac{1}{T_{U}}\right)}
$$

where $A F_{\text {temp }}$ is the acceleration factor under stressed temperature, $E_{a}$ is the activation energy of failure mechanism, $K$ is the Boltzmann constant which equals $8.617 \times 10^{-5} \mathrm{eV} / \mathrm{K}, T_{A}$ is the accelerated temperature, and $T_{U}$ is the use condition temperature. The accelerated temperature

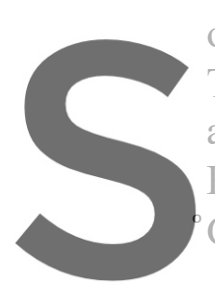
of VIPs samples was The thermal conducti assess VIP thermal perfor HFM 436. The measur C temperature step.

\section{Results}

Register for free at https//www.scipedia.com to download the version without the watermark 3.1 Pristime and Aged Thermall Conductivity

The thermal conductivity of various VIPs with different core panels including fiberglass, fumed silica, compressed microporous silica, and compressed microporous silica with celluloses fiber, were tested in this study. Different types of multilayer films which are common in the market were selected. The employed films include metal foils (AF), metalized films (MF) and polymer films (PF). The most common types can be described as follows:

- AF: In these ones, the thickness of the aluminum in the center is up to 5-10 $\mu \mathrm{m}$ and this layer is laminated by a polyethylene terephthalate (PET) as a protective layer in outer and polyethylene in the inner side of the layer (Wegger et al., 2011; Kalnæs et al., 2014).

- MFs: In these ones, there are three barrier layers of aluminum metalized PET and polyethylene (PE) sheets on the inner side with an aluminum coat of 20-100 nm thickness (Simmler et al., 2005; Ghazi Wakili et al., 2011; Alotaibi, 2014). This is a standard solution to make VIPs applicable in buildings because multiple aluminum layers provide a better impermeable layer in comparison to one-layer aluminum. However, MF type has a low thickness which is an issue as a low thickness results in higher gas and moisture permeance compared to the AF laminates. Table 2 reports the main characteristics of the selected VIPs. 
Table 2. Experimentally characteristics of VIPs provided by manufacturers.

\begin{tabular}{|c|c|c|c|c|c|c|}
\hline $\begin{array}{c}\text { Sample } \\
\text { type }\end{array}$ & $\begin{array}{c}\text { Envelope } \\
\text { type }\end{array}$ & $\begin{array}{c}\text { Thermal } \\
\text { conductivity } \\
(\mathrm{W} / \mathrm{mK})\end{array}$ & $\begin{array}{c}\text { Company } \\
\text { density } \\
\left(\mathrm{kg} / \mathrm{m}^{3}\right)\end{array}$ & Core material & $\begin{array}{r}\text { Pressure } \\
\text { (mbar) }\end{array}$ & 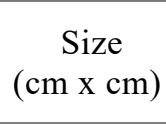 \\
\hline 1 & $N A$ & 0.0028 & 250 & Fibreglass & $\leq 5$ & $30 \times 30$ \\
\hline 2 & MF3 & 0.0048 & 190 & Fumed Silica & $\leq 5$ & $24 \times 13.7$ \\
\hline 3 & MF2 & 0.0037 & 208 & Compressed microporous silica & $\leq 5$ & $30 \times 30$ \\
\hline 4 & MF2 & 0.0070 & 200 & $\begin{array}{c}\text { Compressed microporous silica } \\
+ \text { celluloses fibre }\end{array}$ & $\leq 2$ & $30 \times 30$ \\
\hline 5 & MF2 & 0.0070 & 250 & Compressed microporous silica & $\leq 5$ & $30 \times 30$ \\
\hline
\end{tabular}

The initial thermal conductivity of all samples is shown in Fig. 1. The experimental results validate that fiberglass provides the lowest thermal conductivity; in fact, the core of fiberglass, an open porous composite, allows easier air evacuation (Quenard and Salle, 2005; Kwon et al., 2009). Pressed powder microporous silica would be the second option for high performing VIPs. The results in Fig. 1 shows a generally consistent behaviour of the VIPs and their lower thermal conductivity at lower temperatures (Berardi, 2019).

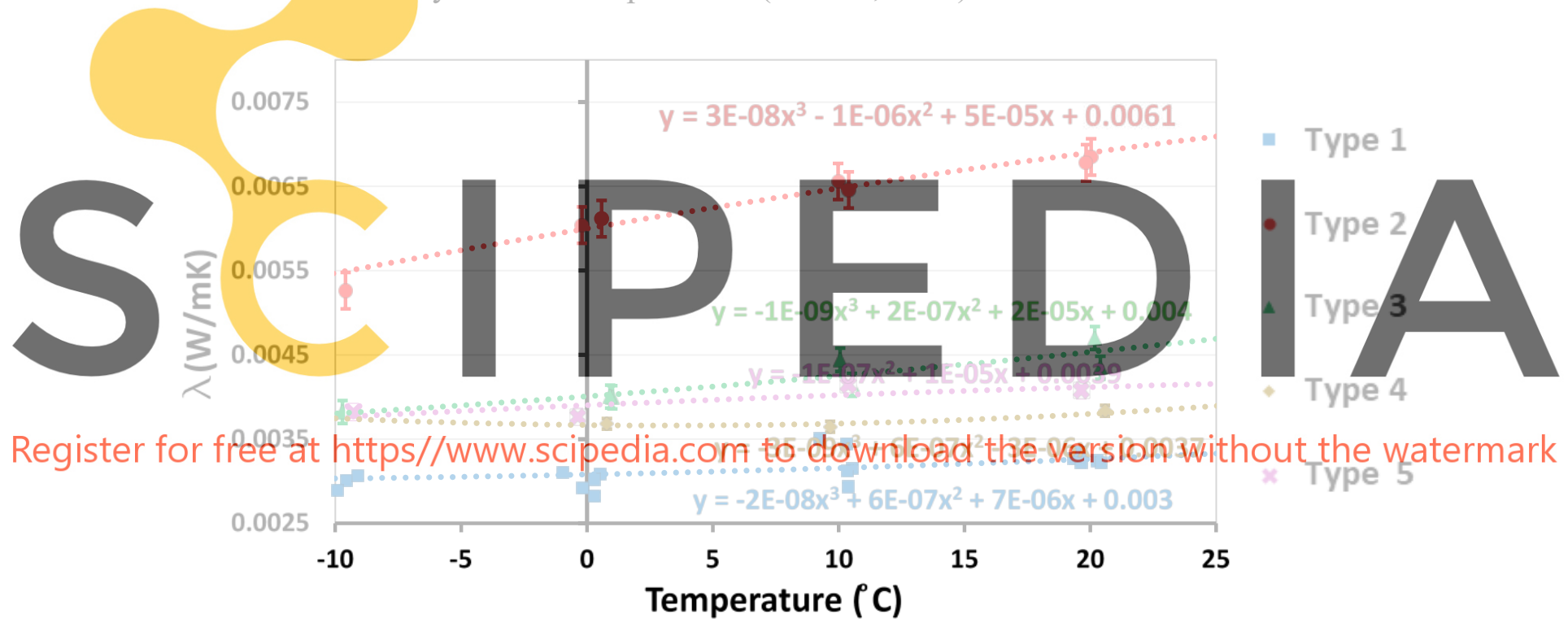

Figure 1. Value of pristine thermal conductivity for five types of VIP samples.

The induced changes in thermal conductivity of VIP samples with the exposure at high temperature, simulating their accelerated aging, are presented in Fig. 2. The results are shown for the average temperature between the two plates of the HFM of $18{ }^{\circ} \mathrm{C}$. The thermal conductivity results were collected every five years of aging for each type of sample.

As can be seen in Fig. 2, Types 1 to 5 have a close initial thermal conductivity in the range from $0.003 \mathrm{~W} / \mathrm{mK}$ to $0.0045 \mathrm{~W} / \mathrm{mK}$. While Type 1 with fiberglass core has the lowest initial thermal conductivity in comparison to the other samples, an increasing trend of thermal conductivity occurred compared to the other types in the same size. Types 3,4 and 5 have an approximately constant thermal conductivity over 25 years. The type of the envelope and the thickness of the foil through the laminate affected the thermal conductivity. In fact, Type 5 which had an MF3 envelope showed minimal aging effects. 


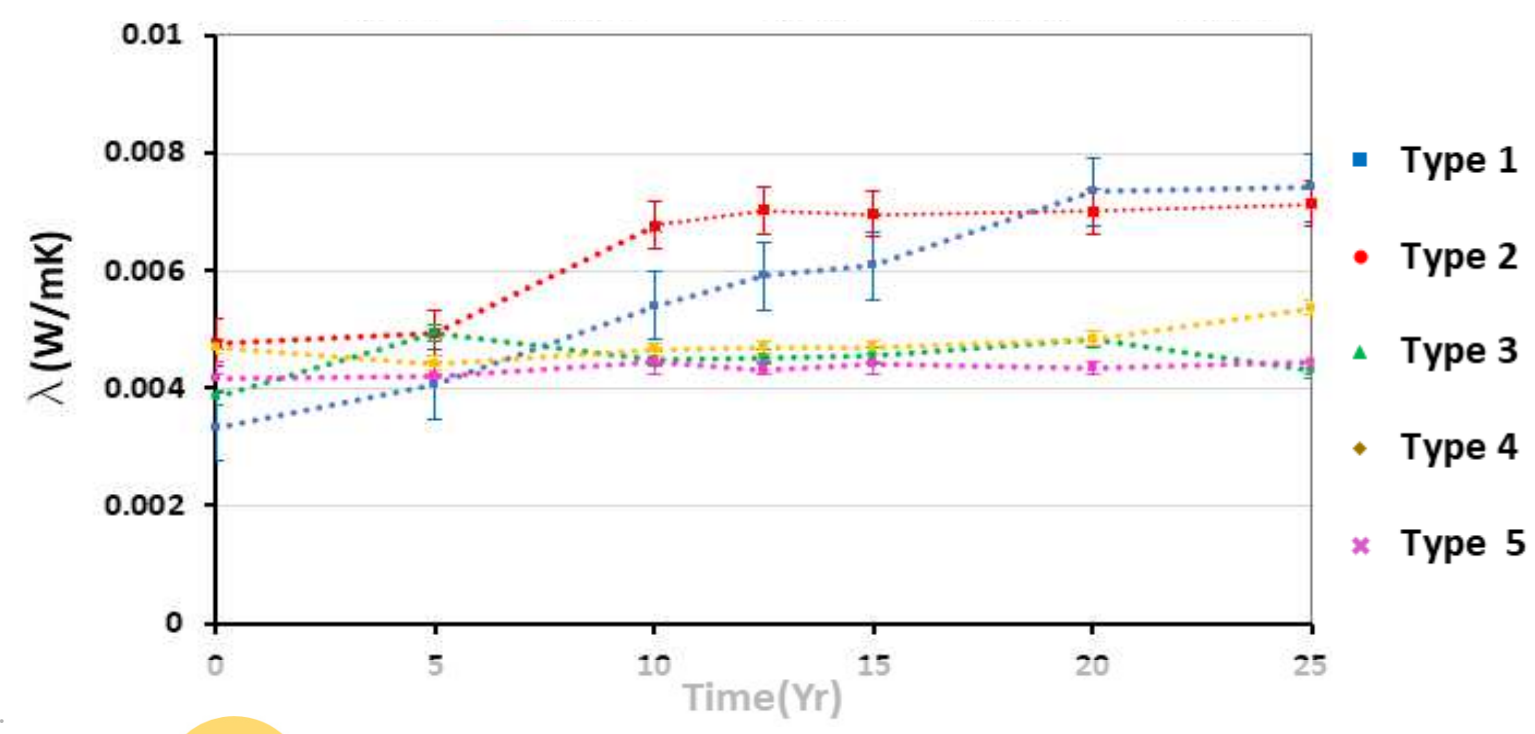

Figure 2. Dynamic variation with the accelerated aging of the thermal conductivity of the VIPs at $18^{\circ} \mathrm{C}$.

\subsection{Ageing Model Verification}

Here, the studies in (Simmler et al. 2005b; Kim 2017, Mukhopadhyaya et al., 2011) are used as a reference model for evaluating the thermal conductivity trend. According to these papers,

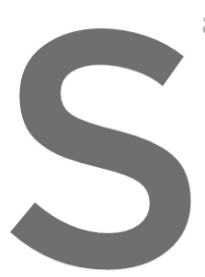

a simple version of the ageing thermal conductivity is:
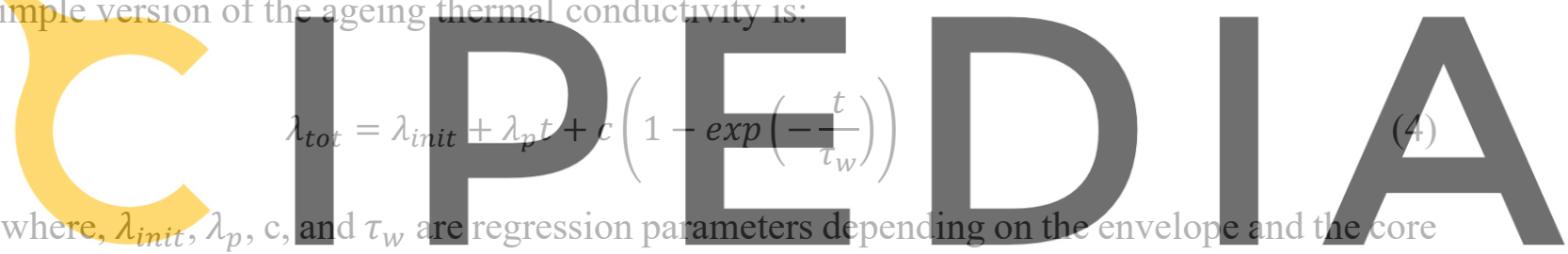

material. The parameters used in (Kim, 2017) are given in Table 3 as the reference model. In

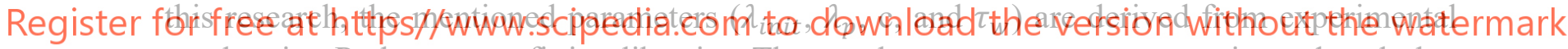
result using Python curve fitting libraries. These unknown parameters are estimated such that the difference between the measured data and the model output is minimum. Table 3 lists these parameters for each sample and parameters in (Kim, 2017) as the reference.

Table 3. Parameters measured for samples under test and reference data proposed by Kim (2017).

\begin{tabular}{ccccc}
\hline Parameters & $\begin{array}{c}\lambda_{\text {init }} \\
(\mathrm{mW} / \mathrm{m} \mathrm{K})\end{array}$ & $\begin{array}{c}\lambda_{\mathrm{p}} \\
(\mathrm{mW} / \mathrm{m} . \mathrm{K} . \mathrm{year})\end{array}$ & $\begin{array}{c}\mathrm{c} \\
(\mathrm{mW} / \mathrm{m} \mathrm{K})\end{array}$ & $\begin{array}{c}\tau_{w} \\
(\text { year })\end{array}$ \\
\hline Reference Model (Kim 2017) & 3.9 to 4.8 & 0.07 & 3.2 & 35.6 \\
Type 1 & 3.20 & 0.17 & 1.30 & 35.6 \\
Type 2 & 4.20 & 0.07 & 2.20 & 20.0 \\
Type 3 & 4.00 & 0.05 & 0.66 & 35.6 \\
Type 4 & 4.00 & 0.05 & 0.66 & 35.6 \\
Type 5 & 4.08 & 0.019 & 0.02 & 35.6 \\
\hline
\end{tabular}

Figure 3 shows the thermal conductivity behaviour of these samples over 25 years. As it can be seen from this figure, overall, the thermal conductivity shows a linear trend over time for these samples. For Type 1, thermal conductivity measurements follow the reference model very well. The trend starts from $0.003 \mathrm{~W} / \mathrm{mK}$ and uniformly increases to $0.008 \mathrm{~W} / \mathrm{mK}$, with a slope of $0.0002 \mathrm{~W} / \mathrm{mK}$ per year. The thermal conductivity in this sample approximately increases by 
$160 \%$ over 25 years. In this type of sample, based on Table 3 , the effect of $\lambda_{p}$ is dominant. For Type 3 , the thermal conductivity value increases by about $70 \%$ over 25 years, as thermal conductivity begins with $0.0041 \mathrm{~W} / \mathrm{mK}$ and slowly reaches $0.0045 \mathrm{~W} / \mathrm{mK}$. Figure 3 shows a small increase for Type 4 thermal conductivity measurement over time, where thermal conductivity starts from $0.0041 \mathrm{~W} / \mathrm{mK}$ and reaches to $0.0055 \mathrm{~W} / \mathrm{mK}$ and it shows $34 \%$ of thermal conductivity increase. This thermal conductivity shows a linear trend with a slope of $0.00006 \mathrm{~W} / \mathrm{mK}$ per year. Type 5 has a trend with a thermal conductivity raises up to $10 \%$, and based on Table 3 , it has a low gas thermal conductivity.
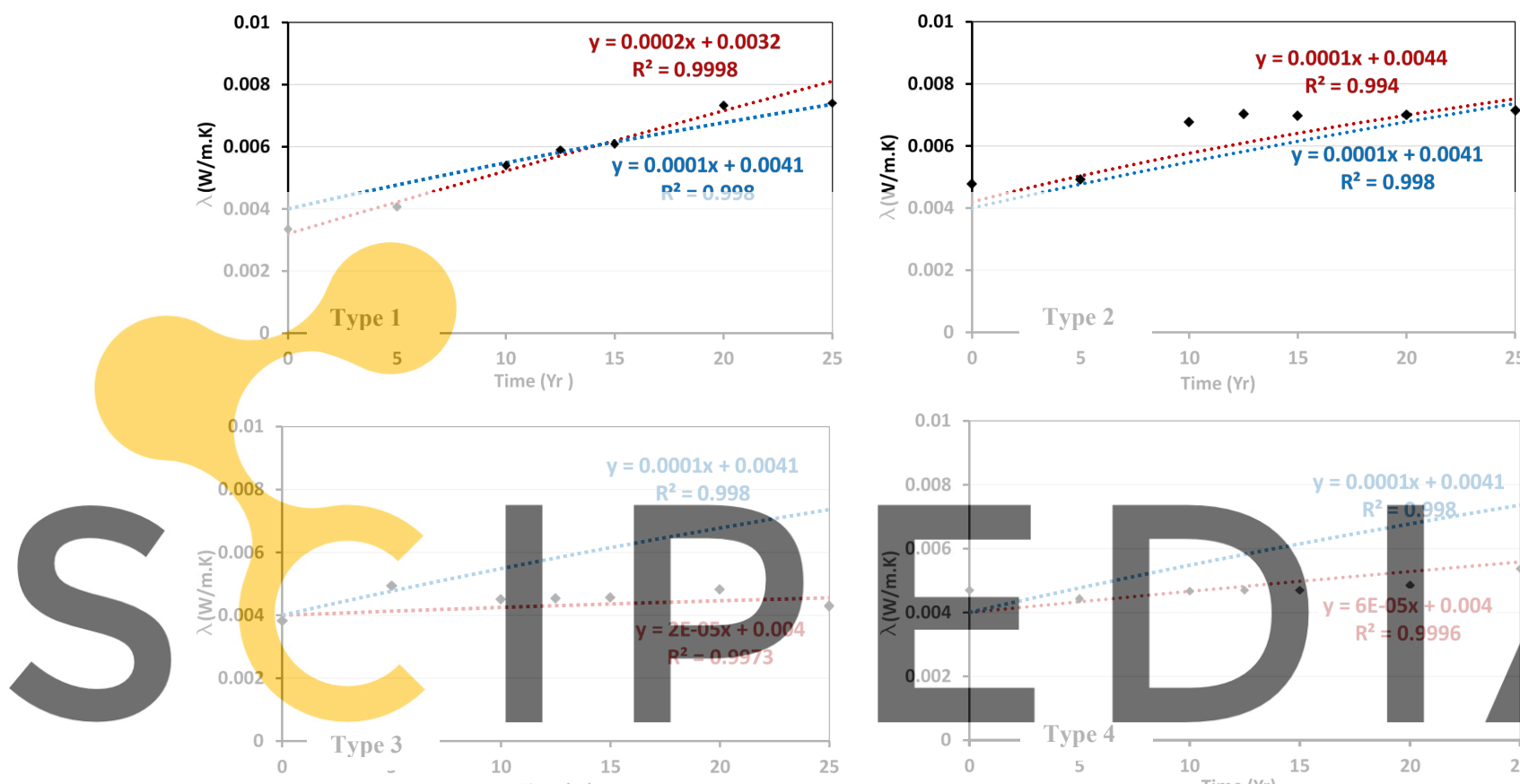

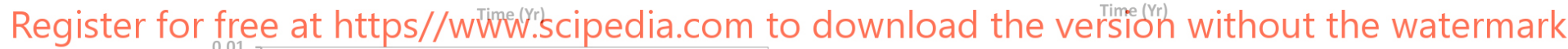
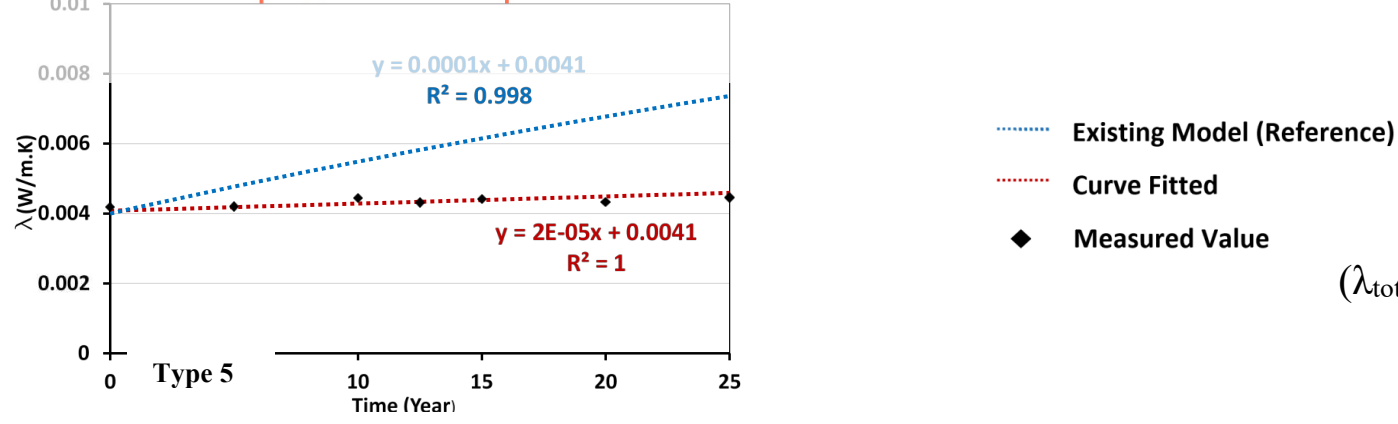

Figure 3. Thermal conductivity trend for different VIPs over time.

\section{Discussion and Conclusions}

Service life is one of the main characteristics of VIP assessment. The threshold value for the first definition of service life (ASTM C1484) is assumed to be $0.008 \mathrm{~W} / \mathrm{mK}$ and $0.011 \mathrm{~W} / \mathrm{mK}$ based on different references (Tenpierik et al., 2010).

The threshold limitation and the service life of each specimen are reported in Table . Types 3 and 5 have the most extended service life among other types, formerly it followed by Types 4,2 , and 1 respectively. 
Table 4. Service life of VIPs samples under test.

\begin{tabular}{lccccc}
\hline & Sample 1 & Sample 2 & Sample 3 & Sample 4 & Sample 5 \\
\hline Service life for 0.008 W/mK & 25 years & 30 years & $>100$ years & 70 years & $>100$ years \\
Service life for 0.011 W/mK & 40 years & 65 years & $>100$ years & $>100$ years & $>100$ years \\
\hline
\end{tabular}

The primary variables which define the quality of VIPs are the density of the core, the transmission rates of gas, and water vapor through the film barrier. Here, the test results collected from thermal conductivity measurements show that the thermal performance of the samples is mainly affected by temperature and, the amount of effect by moisture is minimal as they were also exposed to different levels of humidity without any appreciable results.

The analysis of the collected results represents that gas permeance is the factor that has the most considerable influence on VIP performance. The obtained results of Sample 1, 2 prove that the thermal resistance of the vacuum insulation panels reduces over time because of their higher gas and moisture transmittance. The thermal performances of Types 3, 4 and 5 are more stable. By comparing Types 1 and 3, it is obvious that the core materials with lower pore sizes have longer life spans due to less gas concentration. More results are reported in the paper Berardi et al. (2020).

Overall, the experimental analysis shows that:

The thermal conductivity increases about $1 \%-2.5 \%, 2 \%$, and $5 \%-11 \%$ a year, on average for compressed microporous silica-based, for compressed microporous silica with cellulose

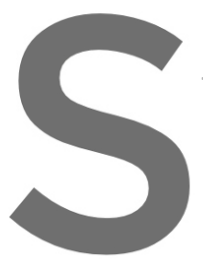

fiber, and for conip

A small variation

fiberglass-based cor

material porosity is

performance of

fiberglass over time.
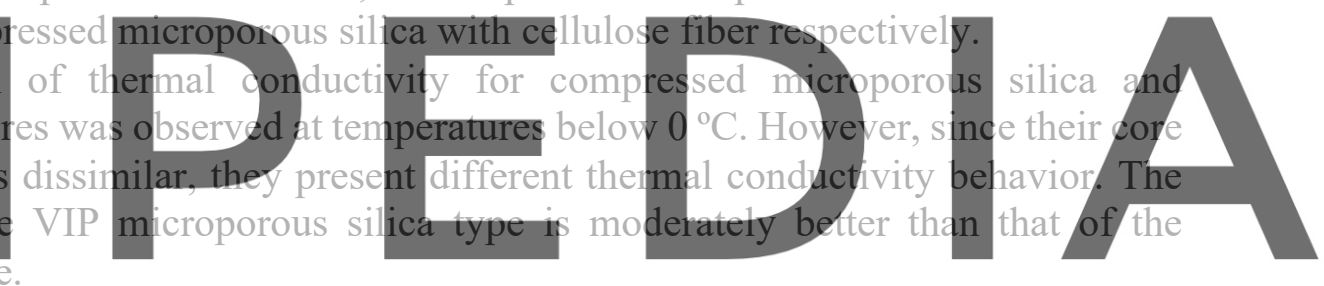

Although the initial thermal conductivity of VIP with fiberglass core is less than that of the

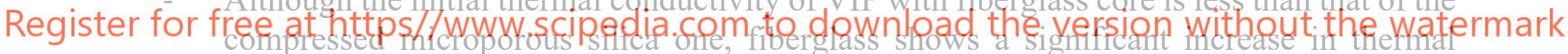

\section{conductivity after aging.}

- The numerical reference model used by NRC is adapted for VIPs with fumed silica and fiberglass-based core material. However, a different mathematical model needs to be developed for compressed microporous silica and compressed microporous silica with cellulose. A significant mismatch is observed between the theoretical model plotted in Fig. 3 , and the measurement results of these types.

\section{ORCID}

Umberto Berardi: https://orcid.org/0000-0002-0508-6195

\section{References}

Alotaibi, S.S. and Riffat, S. (2014). Vacuum insulated panels for sustainable buildings: a review of research and applications. International Journal of Energy Research, 38(1), 1-19, doi: 10.1002/er.3101

ASTM 1484 - American Society for Testing and Materials. (2018) Standard Specification for Vacuum Insulation Panels.

ASTM C518 - American Society for Testing and Materials. (2017). Standard Test Method for Steady-State Thermal Transmission Properties by Means of the Heat Flow Meter Apparatus.

Baetens, R., Jelle, B.P., Thue, J.V., Tenpierik, M.J., Grynning, S., Uvslokk, S. and Gustavsen, A. (2010). Vacuum insulation panels for building applications: A review and beyond. Energy and Buildings, 42(2), 147-172. doi: 10.1016/j.enbuild.2009.09.005 
Batard, A., Duforestel, T., Flandin, L. and Yrieix, B. (2018). Modelling of long-term hygro-thermal behaviour of vacuum insulation panels. Energy and Buildings, 173, 252-267. doi: 10.1016/j.enbuild.2018.04.041

Berardi, U. Nikafkar, M. Wi, S. and Kim, S. (2020) Experimental verification of the theoretical aging of vacuum insulated panels, Journal of Industrial \& Engineering Chemistry.

Berardi U. (2017). A cross country comparison of building energy consumption and their trends, Resource Conservation and Recycling, 123, 230-241, doi: 10.1016/j.resconrec.2016.03.014

Berardi U. (2019). The impact of aging and environmental conditions on the effective thermal conductivity of several foam materials, Energy, 182, 777-794, doi: 10.1016/j.energy.2019.06.022

Caps, R., Beyrichen, H., Kraus, D. and Weismann, S. (2008). Quality control of vacuum insulation panels: Methods of measuring gas pressure. Vacum 82, 691-699. doi: 10.1016/j.vacuum.2007.10.015

Isaia, F., Fantucci, S., Capozzoli, A. and Perino, M. (2017). Thermal bridges in vacuum insulation panels at building scale. Proceedings of the Institution of Civil Engineers: Engineering Sustainability, 170(1), 47-60. doi: 10.1680/jensu. 15.00057

Jelle, P. (2012). Evaluation of Building Products by Conducting Accelerated Climate Ageing in the Laboratory, (7465), 1-9. https://www.irbnet.de/

Johansson, P., Geving, S., Hagentoft, C. E., Jelle, B. P., Rognvik, E., Kalagasidis, A. S. and Time, B. (2014). Interior insulation retrofit of a historical brick wall using vacuum insulation panels: Hygrothermal numerical simulations and laboratory investigations. Building and Environment, 79, 31-45. doi: 10.1016/j.buildenv.2014.04.014

Kalnæs, S. and Jelle, B. (2014). Vacuum insulation panel products: A state-of-the-art review and future research pathways. Applied Energy, 116(7465), 355-375. doi: 10.1016/j.apenergy.2013.11.032

Karami, P., Al-Ayish, N. and Gudmundsson, K. (2015). A comparative study of the environmental impact of Swedish residential buildings with vacuum insulation panels. Energy and Buildings, 109, 183-194. doi: 10.1016/j.enbuild.2015.10.031

Kim, J.H. (2017). Aging performance evaluation of vacuum insulation panel (VIP). Case Studies in Construction Materials 7, 329-335.

Kucukpinar, E., Miesbaue of transparent and opaqu 417. doi: 10.1016/j.egyp

Kunic, R. (2012). Vacuun
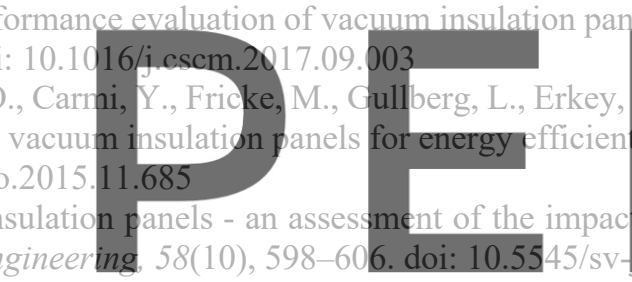

Journal of Mechanical E

Kwon, J., Jang, C. H., Jung, H. and Song, T. (2009). Effective thermal conductivity of various filling materials for

Register for focum insulation panels. International Journal of Heat and Mass Transfer, 52(23-24), 5525-5532. doi:

Lorenzati, A., Fantucci, S. Capozzoli, A. and Perino, M. (2017). The Effect of Temperature on Thermal Performance of Fumed Silica Based Vacuum Insulation Panels for Buildings. Energy Procedia 111, 490-99, doi: 10.1016/j.egypro.2017.03.211.

MacLean, D., Mukhopadhyaya, P., Korn, J. and Mooney, S. (2017). Design Details and Long-Term Performance of VIPs in Canada's North. Energy Procedia 111, 481-89, doi: 10.1016/j.egypro.2017.03.210.

Mukhopadhyaya P., M.K. Kumaran, G. Sherrer and D. Van Reenen (NRC-IRC).(2011) An Investigation on Long-Term Thermal Performance of Vacuum Insulation Panels.

Pons, E., Yrieix, B. and Brunner, S. (2018). Evaluation of VIPs after Mild Artificial Aging during 10 Years : Focus on the Core Behavior. Energy and Buildings 162, 198-207. doi: 10.1016/j.enbuild.2017.12.016

Quenard, D. and Sallee H. (2005) Micro-Nano Porous Materials for High Performance Thermal Insulation MicroNano Porous Materials for High Performance. 2nd International Symposium on Nanotechnology In Construction.

Schwab, H., Heinemann, U., Beck, A., Ebert, H.P. and Fricke. J. (2005) Prediction of Service Life for Vacuum Insulation Panels with Fumed Silica Kernel and Foil Cover. Journal of Thermal Envelope and Building Science, 28(4), 357-74, doi: 10.1177/1097196305051894.

Simmler, H. and S. Brunner. (2005). Vacuum Insulation Panels for Building Application: Basic Properties, Aging Mechanisms and Service Life. Energy and Buildings 37(11), 1122-31, doi: 10.1016/j.enbuild.2005.06.015.

Wegger, E., Petter, B., Sveipe, E. and Grynning, S. (2010). Ageing Effects on Thermal Properties and Service Life of Vacuum Insulation Panels. Building Physics 35, 128-167, doi: 10.1177/1744259111398635. 